\title{
PERBANDINGAN LUARAN SEKSIO SESAREA DENGAN ANESTESI UMUM DAN SPINAL: PERUBAHAN KADAR HEMOGLOBIN, HEMATOKRIT IBU DAN SKOR APGAR BAYI
}

\author{
Ifrinda Giantari ${ }^{1}$, Ibnu Pranoto ${ }^{2}$, Risanto Siswosudarmo ${ }^{3}$
}

\begin{abstract}
Background: Cesarean section is the most common surgical procedure in obstetrics. In 2008, nearly a third of deliveries was done by cesarean section. Two types of anestesi are used in cesarean section i.e., general and regional anestesi with their advantages and disadvantages. General anestesi is often used in emergency cases but is often associated with greater risk of blood loss during surgery and depression of central nervous system of the newborn. Based on these facts, the decision of the type of anesthesia for cesarean section is still debated. Objective: To compare the effects between general and spinal anestesi in the alteration of maternal hemoglobin and hematocrit levels and the neonatal Apgar score.

Method: This study was conducted at Setjonegoro Hospital Wonosobo, Banjarnegara, and Sardjito Hospital Yogyakarta between September to December 2010. Patients undergoing cesarean section, who met inclusion and exclusion criteria were included in this study. Hemoglobin and hematocrit levels before and 6-12 hours after surgery were recorded, as well as the first minute Apgar score. Chi-square and t-test were used for statistical analysis.

Results and Discussion: A total of 114 patients consisting of 59 cases for general anestesi and 55 for spinal groups were recruited. They were comparable in terms of maternal age, age of gestation, parity, BMI and indication of operation. Hemoglobin and hematocrit levels before surgery were also comparable.

The decrease of hemoglobin level after operation in the group of general anesthesia was greater than in the spinal group $(1,75 \pm 1,09 \mathrm{mg} / \mathrm{dL}$ vs $1,00 \pm 0,96 \mathrm{mg} / \mathrm{d} ; \mathrm{p}=0,00)$. The same was seen in the decrease of hematocrit level $(4,47 \pm 2,77 \%$ vs $3,26 \pm 3,04 \%, p=0,02)$. There were 28 cases of asphyxia in the group of general compared to 22 cases in the group of spinal anestesi, but it was not statistically different ( $R R$ 1,16; 95\% $\mathrm{Cl} 0,81-1,65$ ).

Conclusion: The decreased level of hemoglobin and hematocrit after cesarean section in general anesthesia were higher than spinal anesthesia group, although the difference was not clinically significant. There was no significant difference in the incidence of asphyxia at first minute in both groups.
\end{abstract}

Keywords: general anestesi, spinal anesthesia, cesarean section, hemoglobin, hematocrit, Apgar score

\begin{abstract}
ABSTRAK
Latar belakang: Seksio sesarea merupakan prosedur operatif obstetri yang paling sering dilakukan. Pada tahun 2008, hampir sepertiga dari persalinan dilakukan dengan cara seksio sesarea. Dua jenis anestesi sering digunakan yakni anestesi umum dan spinal yang masing-masing mempunyai kelebihan dan kekurangannya. Anestesi umum sering digunakan pada kasus kedaruratan meskipun sering dikaitkan dengan risiko kehilangan darah yang lebih besar dan penekanan pada susunan syaraf pusat bayi. Anestesi spinal sering dikaitkan dengan keadaan hipotensi maternal.

Tujuan: Membandingkan penurunan kadar hemoglobin dan hematokrit ibu dan skor Apgar bayi pada seksio sesarea dengan anestesi umum dan spinal.
\end{abstract}

Peserta PPDS I Obstetri Ginekologi, Bagian OBSGIN Fakultas Kedokteran UGM

2,3 Bagian OBSGIN Fakultas Kedokteran UGM 
Metode: Kohort prospektif.Penelitian dilakukan di RS Setjonegoro Wonosobo, RS Banjarnegara, dan RS Sardjito pada bulan September sampai Desember 2010. Pasien yang menjalani seksio sesarea dan memenuhi kriteria inklusi dan eksklusi dimasukkan dalam penelitian ini. Sampel penelitian diikuti sesuai dengan kelompok jenis anestesi. Kadar hemoglobin dan hematokrit sebelum operasi dan 6-12 jam sesudah operasi serta skor Apgar 1 menit dicatat. X-square dan t-test dipakai untuk analisis data.

Hasil dan Pembahasan: Sebanyak 114 kasus seksio sesarea memenuhi kriteria kelayakan, yang terdiri dari 59 kasus kelompok anestesi umum dan 55 kasus anestesi spinal. Kedua kelompok komparabel dalam hal umur, umur kehamilan, paritas BMI dan indikasi operasi. Demikian juga kadar hemoglobin dan hematokrit sebelum operasi, tidak menunjukkan perbedaan yang bermakna. Penurunan kadar hemoglobin setelah operasi pada kelompok anestesi umum lebih besar dibanding kelompok spinal $(1,75 \pm 1,09 \mathrm{mg} / \mathrm{dL}$ vs 1,00 $\pm 0,96 \mathrm{mg} / \mathrm{d}$; $p=0,00)$, demikian juga penurunan kadar hematocrit $(4,47 \pm 2,77 \%$ vs $3,26 \pm 3,04 \%, p=0,02)$. Pada penilaian menit pertama terdapat 28 kasus asfiksia (skor Apgar <6) pada kelompok anestesi umum dan 22 kasus pada kelompok anestesi spinal $(R R 1,16,95 \% C l 0,81-1,65)$, tetapi tidak bermakna secara statistik $(p=0,42)$.

Kesimpulan: Terdapat penurunan kadar hemoglobin dan hematokrit ibu yang bermakna pada kelompok yang menjalani seksio sesarea dengan anestesi umum meskipun secara klinis tidak bermakna. Tidak terdapat perbedaan bermakna secara statistik pada kejadian asfiksia pada menit pertama.

Kata kunci: anestesi umum, anestesi spinal, seksio sesarea, hemoglobin, hematokrit, skor Apgar

\section{PENDAHULUAN}

Angka kejadian seksio sesaera menurut WHO adalah antara $10-20 \%$ persalinan dan meningkat hampir sepertiga pada tahun 2008 . Kurang lebih $12 \%$ kematian terkait dengan seksio sesarea adalah akibat perdarahan. Beberapa faktor yang mempengaruhi perdarahan selama dilakukan seksio sesarea adalah jenis anestesi, kelainan letak plasenta, kelainan sistemik ibu, teknik operasi dan penyulit yang dihadapi selama operasi. ${ }^{1}$ Jenis anestesi yang digunakan bervariasi, meskipun pada umumnya hanya dua jenis yakni anestesi umum dan regional, baik spinal maupun epidural yang masing-masing mempunyai pengaruh yang berbeda pada ibu maupun janinnya.

Anestesi umum menghilangkan nyeri dengan menghilangkan kesadaran dengan obat-obatan yang diberikan melalui intravena maupun melalui inhalasi. Keuntungan menggunakan anestesi umum pada seksio sesarea adalah dapat melakukan induksi dengan cepat, sehingga tepat digunakan untuk seksio sesarea yang bersifat crash emergency. Kendala yang sering dihadapi dengan menggunakan jenis anestesi ini adalah aspirasi cairan lambung dan gagalnya intubasi. Beberapa penelitian terdahulu menyatakan bahwa obat-obatan yang digunakan untuk anestesi umum mempengaruhi kontraksi uterus dan dapat melewati barier plasenta sehingga akan meningkatkan jumlah perdarahan selama dilakukan seksio sesarea dan menurunkan nilai Apgar bayi. $^{2}$

Penggunaan anestesi umum atau spinal untuk tindakan seksio sesarea masih diperdebatkan, sehingga pemilihan jenis anestesi yang tepat untuk seksio sesarea sangat diperlukan.

\section{METODE}

Penelitian dilakukan dengan metode kohort prospektif yang menganalisis pengaruh jenis anestesi terhadap penurunan hemoglobin dan hematokrit ibu serta skor Apgar bayi baru lahir. Jenis anestesi ditentukan oleh ahli anestesi sesuai dengan kemampuan dan ketersediaan tenaga serta alat dan bahan. Populasi penelitian adalah semua pasien yang dilakukan seksio sesarea di RS Wonosobo, RS Banjarnegara dan RS Sardjito Yogyakarta pada bulan September sampai Desember 2010. Kriteria inklusi meliputi keadaan umum baik, janin tunggal hidup, tanda vital dan hasil pemeriksaan laboratorium dalam batas keadaan normal. Yang tidak masuk dalam 
penelitian ini adalah ibu hamil dengan riwayat seksio sesarea, ibu dengan kelainan sistemik, kelainan letak plasenta dan mendapatkan transfusi selama atau setelah operasi.

Semua pasien yang memenuhi kriteria kelayakan dimasukkan sebagai subyek penelitian. Mereka diberi penjelasan mengenai penelitian ini, lalu menandatangani informed consent dan surat persetujuan. Subyek penelitian dibagi menjadi 2 kelompok. yaitu seksio sesarea dengan anestesi umum dan seksio sesarea dengan anestesi spinal. Jenis irisan kulit adalah transversal pada kurang lebih $3 \mathrm{~cm}$ di atas simfisis pubis, dan irisan rahim adalah transversal pada segmen bawah rahim.

Pemeriksaan kadar hemoglobin dan hematokrit dilakukan sebelum operasi dilakukan dan diulang 6 jam setelah operasi. Penurunan kadar hemoglobin dan hematokrit ibu merupakan selisih antara kadar hemoglobin dan hematokrit sebelum operasi dan sesudah operasi. Skor Apgar menit pertama bayi baru lahir dilakukan oleh residen ilmu kesehatan.

\section{HASIL DAN PEMBAHASAN}

Selama kurun waktu tersebut terdapat 380 kasus seksio sesarea, 114 kasus memenuhi kriteria inklusi dan eksklusi yang terdiri atas 59 kelompok anestesi umum, dan 55 kelompok anestesi spinal. Dari keseluruhan kasus yang masuk dalam penelitian ini, tidak terdapat kesulitan selama dilakukan operasi. Kedua kedua kelompok adalah sebanding dalam semua variabel luar yang berpotensi sebagai pengganggu.

Tabel 1a. Komparabilitas subyek penelitian berdasarkan umur, BMI, kadar hemoglobin dan hematokrit pre operasi.

\begin{tabular}{lccc}
\hline \multicolumn{1}{c}{ Variabel } & $\begin{array}{c}\text { Anestesi Umum } \\
(\mathrm{n}=59) \\
\text { Mean } \pm S D\end{array}$ & $\begin{array}{c}\text { Anestesi Spinal } \\
(\mathrm{n}=55) \\
\text { Mean } \pm \text { SD }\end{array}$ & $\boldsymbol{p}$ \\
\hline Umur ibu (tahun) & $28,39 \pm 6,54$ & $29,35 \pm 6,45$ & 0,43 \\
BMI $\left(\mathrm{kg} / \mathrm{m}^{2}\right)$ & $26,42 \pm 3,11$ & $26,19 \pm 2,56$ & 0,66 \\
Hemoglobin $(\mathrm{g} / \mathrm{dL})$ & $\mathbf{1 1 , 7 5 \pm 1 , 0 4}$ & $11,58 \pm 1,2$ & 0,50 \\
Hematokrit $(\%)$ & $35,60 \pm 2,92$ & $35,52 \pm 3,09$ & 0,88 \\
\hline
\end{tabular}

Tabel 1b. Komparabilitas subyek penelitian berdasarkan umur kehamilan, paritas dan indikasi operasi

\begin{tabular}{llll}
\hline \multicolumn{1}{c}{ Variabel } & $\begin{array}{c}\text { Anestesi Umum } \\
\mathbf{n}(\%)\end{array}$ & $\begin{array}{c}\text { Anestesi Spinal } \\
\mathbf{n}(\%)\end{array}$ & $\boldsymbol{p}$ \\
\hline $\begin{array}{l}\text { Umur Kehamilan (m inggu) } \\
<37 \text { minggu }\end{array}$ & $5(4,4 \%)$ & $3(2,6 \%)$ & 0,38 \\
$37-40$ minggu & $43(37,7 \%)$ & $46(40,4 \%)$ & \\
$>40$ minggu & $11(9,6 \%)$ & $6(5,3 \%)$ & \\
Paritas & & & 0,21 \\
$\quad$ Primi & $45(39,5 \%)$ & $47(41,2 \%)$ & \\
Multi & $14(12,3 \%)$ & $8(7,0 \%)$ & 0,41 \\
Gawat janin & & & \\
$\quad$ Ya & $7(6,1 \%)$ & $4(3,5 \%)$ & \\
$\quad$ Tidak & $52(45,6 \%)$ & $51(44,7 \%)$ & 0,18 \\
Status persalinan & & $38(33,3 \%)$ & \\
$\quad$ Dalam persalinan & $33(28,9 \%)$ & $17(14,9 \%)$ & \\
$\quad$ Tidak dalam persalinan & $26(37,7 \%)$ &
\end{tabular}


Pemeriksaan kadar hemoglobin dan hematokrit dilakukan kembali 6 jam sesudah operasi. Terdapat penurunan kadar hemoglobin seperti terlihat pada

tabel berikut ini.

Tabel 2a. Penurunan kadar hemoglobin sebelum dan sesudah operasi

\begin{tabular}{llllc}
\hline \multicolumn{1}{c}{ Variabel } & \multicolumn{2}{c}{ Kadar hemoglobin $(\mathrm{g} / \mathrm{dL})$} & Nilai $\mathbf{p}$ \\
\cline { 2 - 5 } & $\begin{array}{l}\text { Sebelum } \\
\text { operasi }\end{array}$ & $\begin{array}{c}\text { Sesudah } \\
\text { operasi }\end{array}$ & $\Delta$ Mean & \\
\hline $\begin{array}{l}\text { Seluruh kasus } \\
\text { (n=114) }\end{array}$ & $11,66 \pm 1,17$ & $10,27 \pm 1,27$ & $1,39 \pm 1,09$ & 0,00 \\
$\begin{array}{l}\text { Anestesi Umum } \\
(\mathrm{n}=59)\end{array}$ & $11,73 \pm 1,04$ & $9,97 \pm 1,06$ & $1,75 \pm 1,09$ & 0,00 \\
$\begin{array}{l}\text { Anestesi Spinal } \\
(\mathrm{n}=55)\end{array}$ & $11,58 \pm 1,20$ & $10,58 \pm 1,41$ & $1,00 \pm 0,96$ & 0,00 \\
\hline
\end{tabular}

Tabel 2 b. Penurunan kadar hematokrit sebelum dan sesudah operasi

\begin{tabular}{|c|c|c|c|c|}
\hline \multirow{2}{*}{ Variabel } & \multicolumn{2}{|c|}{ Kadar hematokrit (\%) } & \multirow{2}{*}{$\Delta$ Mean } & \multirow{2}{*}{$p$} \\
\hline & $\begin{array}{c}\text { Sebelum pperasi } \\
\text { Mean } \pm \text { SD }\end{array}$ & $\begin{array}{c}\text { Sesudah operasi } \\
\text { Mean } \pm \text { SD }\end{array}$ & & \\
\hline $\begin{array}{l}\text { Seluruh kasus } \\
(n=114)\end{array}$ & $35,56 \pm 2,99$ & $31,68 \pm 3,36$ & $3,89 \pm 2,95$ & 0,00 \\
\hline $\begin{array}{l}\text { Anestesia } \\
\text { umum }(n=59)\end{array}$ & $35,60 \pm 2,92$ & $31,13 \pm 2,71$ & $4,47 \pm 2,77$ & 0,00 \\
\hline $\begin{array}{l}\text { Anestesia spinal } \\
(\mathrm{n}=55)\end{array}$ & $35,52 \pm 3,09$ & $32,26 \pm 3,87$ & $3,26 \pm 3,04$ & 0,00 \\
\hline
\end{tabular}

Bila dilihat penurunan kadar hemoglobin dan hematokrit sebelum dan sesudah operasi antara kelompok yang mendapat anestesi umum dan spinal maka terlihat bahwa perbedaan tersebut sangat kecil yang secara klinis tidak berarti meskipun secara statistik bermakna (Tabel 3a dan 3b).

Tabel 3a. Pengaruh jenis anestesi terhadap penurunan kadar hemoglobin

\begin{tabular}{|c|c|c|c|}
\hline \multirow{2}{*}{ Variabel } & \multicolumn{2}{|c|}{ Penurunan kadar hemoglobin $(\mathrm{g} / \mathrm{dL})$} & \multirow{2}{*}{$p$} \\
\hline & Mean $\pm S D$ & $\Delta$ Mean $(95 \% \mathrm{Cl})$ & \\
\hline Anestesi Umum ( $n=59)$ & $1,75 \pm 1,09$ & \multirow{2}{*}{$0,75(0,37-1,13)$} & \multirow{2}{*}{0,00} \\
\hline Anestesi Spinal $(n=55)$ & $1,00 \pm 0,96$ & & \\
\hline
\end{tabular}

Tabel 3b. Pengaruh jenis anestesi terhadap penurunan kadar hematokrit

\begin{tabular}{|c|c|c|c|}
\hline \multirow{2}{*}{ Variabel } & \multicolumn{2}{|c|}{ Penurunan kadar hematokrit (\%) } & \multirow{2}{*}{$p$} \\
\hline & Mean $\pm S D$ & $\Delta$ Mean $(95 \% \mathrm{Cl})$ & \\
\hline Anestesi umum ( $n=59$ ) & $4,47 \pm 2,77$ & \multirow{2}{*}{$1,21(1,40-2,49)$} & \multirow{2}{*}{0,02} \\
\hline Anestesi spinal $(n=55)$ & $3,26 \pm 3,04$ & & \\
\hline
\end{tabular}


Bila dilihat pengaruh jenis anestesi terhadap kejadian asfiksia (skor Apgar $<7$ ) bayi baru lahir maka terlihat bahwa kejadian asfiksia pada kelompok pasien dengan anestesi umum lebih tinggi meskipun secara statistik tidak bermakna (Tabel 4).

Tabel 4. Pengaruh jenis anestesi terhadap kejadian asfiksia bayi baru lahir

\begin{tabular}{ccccccc}
\hline \multirow{2}{*}{ Variabel } & \multicolumn{3}{c}{ Asfiksia } & & \multirow{2}{*}{ RR (95\% Cl) } & Nilai p \\
\cline { 2 - 5 } & Ya & Tidak & asfiksia & & \\
\hline Anestesi umum $(n=59)$ & 28 & 31 & 47,46 & $1,18(0,81-1,65)$ & 0,42 \\
Anestesi spinal $(n=55)$ & 22 & 33 & 40,00 & & \\
\hline
\end{tabular}

Rerata kadar hemoglobin sebelum operasi adalah pada seluruh kasus adalah $11,66 \pm 1,17 \mathrm{~g} / \mathrm{dL}$, dengan kadar terendah $9,10 \mathrm{~g} / \mathrm{dL}$ dan tertingi 14,90 $\mathrm{g} / \mathrm{dL}$. Terdapat penurunan kadar hemoglobin (kadar hemoglobin sebelum dikurangi sesudah operasi) dengan nilai rerata menjadi $10,27 \pm 1,27 \mathrm{~g} / \mathrm{dL}$ (kadar terendah 7,30 g/dL dan tertinggi $14,70 \mathrm{~g} / \mathrm{dL}$ ). Secara klinis perbedaan tersebut sebesar $1,39 \mathrm{~g} / \mathrm{dL}$ atau penurunan sebesar $11,9 \%$. Bila dilihat berdasar kelompok anestesi umum dan spinal, tampak rerata kadar hemoglobin sebelum operasi sedikit lebih tinggi pada kelompok anestesi umum dengan rerata 11,73 $\pm 1,04 \mathrm{~g} / \mathrm{dL}$ vs. $11,58 \pm 1,20 \mathrm{~g} / \mathrm{dL}$, tetapi pada saat sesudah operasi rerata kadar hemoglobn pada kelompok anestesi umum lebih rendah daripada kelompok anestesi spinal (Tabel 2a).

Bila dilihat pada penurunan kadar hemoglobin maka nampak bahwa penurunan kadar hemoglobin pada kelompok anestesi umum lebih tinggi dibanding kelompok anestesi spinal. Perbedaan rata-rata pada kelompok anestesi umum adalah 1,75 $\pm 1,09 \mathrm{mg} / \mathrm{dL}$ dibanding 1,00 $\pm 0,96 \mathrm{mg} / \mathrm{dL}$ pada kelompok anestesi spinal (Tabel 3a). Secara statistik perbedaan tersebut bermakna meskipun secara klinis bisa dikatakan tidak karena hanya berbeda 0,75 mg/dL.

Hal yang sama terjadi pada perubahan kadar hematokrit. Secara umum terjadi penurunan kadar hematokrit dari $35,56 \pm 2,99 \%$ menjadi $31,68 \pm 3,36$, atau penurunan sebesar $10,9 \%$. Perbedaan tersebut secara statistik sangat bermakna meskipun secara klinis tidak terlalu berarti (Tabel 2b). Bila dilihat perbandingan penurunan kadar hematokrit pada kedua kelompok terlihat bahwa penurunan hematokrit pada kelompok anestesi umum secara rata-rata lebih tinggi dibanding kelompok anestesi spinal, yakni $4,47 \pm 2,77 \%$ dibanding 3,26 $\pm 3,04 \%$, yang secara statistik perbedaan tersebut cukup bermakna, meskipun secara klinis sebuah perbedaan sebesar $1,21 \%$ dapat dianggap tidak terlalu berarti (Tabel 3b).

Hasil penelitian ini tidak berbeda dengan penelitian lainyang mendapatkan rerata kadar haemoglobin dan hematokrit sebelum operasi masing-masing $11.84 \pm 7.7 \mathrm{~g} / \mathrm{dL}$ dan $33.3 \pm 3.4 \%$, dan rerata setelah operasi masing-masing $10.3 \pm 6.4 \mathrm{~g} /$ $\mathrm{dL}$ dan $28.9 \pm 4.1 \%$, yang setara dengan kehilangan darah $787 \pm 519 \mathrm{ml}$. Penelitian serupa juga diperoleh oleh Lertakyamanee dan Gilstrap yang mendapatkan penurunan kadar hematocrit menjadi kurang lebih $30 \% .^{3,4}$

Lebih jauh Gilstrap mengemukakan bahwa penambahan halogen pada anestesi umum yang menggunakan nitrit oxide meningkatkan risiko pasien mendapatkan transfusi dan kejadian anemia postpartum. ${ }^{4}$ Pasien yang mendapatkan halotan mempunyai hematokrit pascasalin kurang dari $30 \%$ dan mengalami penurunan hematokrit $8 \%$ lebih banyak daripada yang tidak mendapatkan halotan. Hal ini disebabkan agen terhalogenasi mengganggu kontraksi uterus sehingga berpotensi meningkatkan kehilangan darah selama operasi. ${ }^{5}$ Pada penelitian ini agen yang digunakan pada anestesi umum adalah 
enfluran dan propofol. Enfluran merupakan obat anestesi inhalasi dalam golongan halotan yang mempengaruhi kontraksi otot polos, sedangkan propofol merupakan obat induksi anestesi yang mempengaruhi tekanan darah ibu melalui mekanisme dalam menurunkan resistensi vaskuler sistemik, sehingga aliran darah uterus diturunkan. ${ }^{5}$

Jenis anestesi yang digunakan diduga mempengaruhi morbiditas pada ibu dan bayi pada tindakan seksio sesarea. Morbiditas jangka pendek yang dipengaruhi oleh jenis anestesi adalah jumlah perdarahan seperti dan asfiksia bayi. ${ }^{6}$ Pada penelitian ini kejadian asfiksia (skor Apgar < 7) pada menit pertama pada seluruh kasus adalah 50 (43,9\%) yang terdiri dari 28 kasus $(24,6 \%)$ pada kelompok anestesi umum dan 22 kasus (19,3\%) pada kelompok anestesi spinal, atau perbedaan sebesar 5,3\%. Tampak pada anestesi umum kejadian asfiksi lebih tinggi, meskipun secara statistik tidak bermakna. Peneliti lain yang membandingkan luaran bayi pada seksio sesarea dengan anestesi umum dan anestesi regional mendapatkan skor Apgar bayi pada menit pertama tidak berbeda bermakna pada kedua kelompok, meskipun pada menit ke-5 skor Apgar bayi pada kelompok anestesi umum lebih rendah secara bermakna dibanding kelompok anestesi regional. ${ }^{7}$

Asfiksia terjadi akibat hipoksia pada janin, yang salah satu penyebabnya adalah faktor persalinan. Pada persalinan dengan seksio sesarea, asfiksia dapat diakibatkan oleh pemilihan jenis anestesi yang digunakan. Sawar plasenta dilewati hampir semua obat anestesi dengan cara difusi. Karena sawar plasenta dan sawar otak keduanya mempunyai ketentuan yang sama terhadap lipid, maka cara difusi yang terjadi melalui sawar otak juga terjadi di plasenta, dari konsentrasi yang tinggi molekulmolekul tersebut berjalan ke konsentrasi yang rendah untuk mencapai suatu keseimbangan. ${ }^{8,9}$

\section{KESIMPULAN DAN SARAN}

1. Penurunan kadar hemoglobin dan hematokrit ibu yang menjalani seksio sesarea dengan anestesi umum lebih banyak dari pada seksio sesarea dengan anestesi spinal. Meskipun penurunan tersebut secara statistik berbeda, tetapi secara klinis perbedaan tersebut tidak bermakna.

2. Kejadian asfiksia menit pertama bayi baru lahir pada seksio sesarea dengan anestesi umum tidak berbeda bermakna secara dibandingkan dengan seksio sesarea menggunakan anestesia spinal.

Kedua cara anestesi dapat dipakai pada pembedahan seksio sesarea tergantung pada sifat emergensinya dan keterampilan ahli anestesinya.

Diperlukan penelitian lain dengan rancangan penelitian yang lebih baik yaitu Randomized Clinical Trial (RCT).

\section{DAFTAR PUSTAKA}

1. Cuningham FG, Mc Donald PC, Grant NF, Leveno KJ, Gilstrap LC, Hankins GDV, Clark SL. William obstetrics. Philadelphia : WB Saunders, 2010. pp. 1-193.

2. Bengi, ES \& Guldogus F.Comparison of neonatal effects of epidural and general anasthesia for cesarean section. 2003. pp. 41-45.

3. Lertakyamanee, J.comparataion of general and regional anasthesia for cesarean section. s.I. : Journal of medical association of thailand, 1999.

4. Gilstrap, L.Effect of type of anathesia on blood lose at cesarean section. London : national institute for clinical excellence, 2004, p. 328.

5. Andrews, W.Effect of type of anestesi on blood loss at elective repeat cesarean section. Dallas: Departement of obstetrics and gynecology. University of texas Southwestern Medical Center, 1992. p. 197. Vol. 9.

6. Galur, P. Regional anestesi versus general anestesi, morbidity and mortality. 2006. pp. 249-263.

7. Yegin, A.The effects of of epidural anestesi and general anestesi on newborns at cesarean section. s.I. : Turkish journal of medical sciences, 2003, pp. 311-314. 
8. Hong, J.Comparison of general and epidural anestesi in elective cesarean section for placenta previa totalis: maternal hemodinamics, blood loss and neonatal outcome. J. Obstetric Anesthesia. 2003, pp. 12-16.
9. Sener B, Guldogus F, Karakaya D, Baris S, Kocamanoglu S, Tur A. Comparison of neonatal effects of epidural and general anesthesia for cesarean section. Gynecol Obstet Invest 2003; 55: 41-45 